\title{
Practice-based Learning Across and Between the Health professions: A Conceptual Exploration of Definitions and Diversity and their Impact on Interprofessional Education
}

\author{
Jill E. Thistlethwaite \\ University of Queensland, Herston, Australia
}

Corresponding author:

Professor Jill E. Thistlethwaite, School of Medicine, University of Queensland, Herston, Australia 4006

Email: j.thistlethwaite@uq.edu.au,Phone: + 61 (0)7 33655206

\begin{abstract}
Practice-based learning (PrBL) occurs in all health professional training but there are intra- and interprofessional differences depending on context, location and professional identity. In this position paper I will explore the definition, context and elements of PrBL across the health professions, and their implications for interprofessional education (IPE). IPE is a particular focus because of its increasing prominence globally in response to the changing nature of health care delivery as the population ages, the incidence of long term and chronic conditions increases and health and social care delivery is undertaken increasingly in multidisciplinary teams. PrBL aims to facilitate the transfer of theory into the workplace through situated and experiential learning. But it is not solely about preparing for practice after qualification; rather it is about learning in and about practice through authentic experience and becoming part of a community of practice. Best PrBL requires the alignment of explicit learning outcomes with clinically situated and supervised learning activities, and then with valid and reliable assessment. There are still questions about the optimal length and timing of rotations/attachments, and the nature of work-based assessment. The majority of an individual student's PrBL is uniprofessional but there is a global trend towards increasing and enhancing the provision of interprofessional PrBL, despite the logistical and resource implications. This paper is an overview of current trends in PrBL and raises questions about future research and developments.
\end{abstract}

'In everyday organizational life, work, learning, innovation, communication, negotiation, conflict over goals, their interpretation, and history, are co-present in practice. They are part of human existence' (Gherardi 2000, p214).

In this position paper I explore the aims, nature and delivery of practice-based learning (PrBL) in order to introduce the scope of the journal and consider areas for further exploration. 


\section{Introduction and definitions}

There is no commonly accepted definition of practice-based learning (QAA Scotland 2011) but there are elements that feature, implicitly or explicitly, in most definitions (see Table 1). Practice-based learning is a feature of professional and vocational training programmes such as teaching, the health professions, engineering and social work. The term work-integrated learning (WIL) is now also being used and is 'an umbrella term for a range of approaches and strategies that integrate theory with the practice of work within a purposefully designed curriculum' (Patrick et al. 2008, piv). The overall aim of WIL is to produce work-ready graduates, i.e. 'graduates with a combination of content knowledge and employability skills, such as communication, team work and problem solving, which enables effective professional practice' (Patrick et al. 2008, piv). In medical education the more commonly used term is clinical education (in contrast to pre-clinical education which takes place in the university), while other professions use the terms practicum, placement and fieldwork. However, the underlying principle of the application of academic knowledge to the clinical setting is common across the professions; for example, see occupational therapy (Costa \& Burkhardt 2003). PrBL may thus be contrasted with classroom and theory-based learning and is essentially experiential in nature with the goal of reducing the theory-practice gap.

Table 1 Themes and terminology of practice-based learning common across the health professions

- Work-based learning

- Work-integrated learning

- Application of theory to practice

- Aims to enhance employability (QAA Scotland 2011) by supporting students in the development of career management skills (UNISA)

- Embeds industry input into programmes (University of South Australia)

- Supports learners to develop skills to work professionally with their discipline's knowledge (UNISA)

- Importance of role models

- Informal learning and the effects of the hidden curriculum

Professional practice-based learning for qualification is accredited through the standards and frameworks of the relevant professional and regulatory bodies, which are also responsible for evaluating the quality assurance processes of educational experiences. In this paper I focus on PrBL for the health professions. I will consider similarities and differences in the context, learning outcomes, delivery and assessment of PrBL (Table 2) across the health professions and the impact these may have on practice-based interprofessional education (IPE).

Table 2 Elements of PrBL that may vary across the professions

- The learning environment - the clinical setting (e.g. hospital, community)

- Timing, length and type of placement (e.g. integrated, longitudinal, short)

- Learning outcomes (e.g. via the formal, informal and hidden curricula)

- The role of the learner (e.g. supernumerary, apprentice, legitimate peripheral participation)

- Supervision (through mentors, facilitators, tutors preceptors etc.)

- Assessment (e.g. workplace-based, written, OSCE-type, portfolio, viva)

- Teamwork focus (uni, multi or interprofessional) 


\section{The context of PrBL}

'Practice' and practice settings are primarily service delivery environments, which are adapted to varying degrees for educational delivery. It is not only students who are learning in such settings but also junior health professionals (through postgraduate training), and seniors (through continuing professional development). The learning culture of the workplace is important, with skilled facilitation required to optimise the clinical experiences that trigger learning. Learners need to be encouraged to reflect critically and change their practice to enhance their knowledge and skills (Williams 2010).

The word 'practice' itself has multiple meanings depending on the context. We develop skills through practice, though repetition alone is not sufficient as learning requires varied practice (Entwistle 2009) in different settings and with increasing complexity. For all health professions PrBL has a major focus on translating theory into practice: the application of learning through observing and then participating in authentic tasks. However, a stated goal of PrBL as 'preparing for practice' as a qualified health professional has been criticised for downplaying the role of learning itself during practice. This 'notion of preparedness separates learning from practice because it privileges learning as occurring before and outside practice' (Zukas \& Kilminster 2012, p200). PrBI is learning that takes place in practice (the workplace), and through participating in practice, and it is also learning about practice itself (professional work), including its culture and responsibilities.

Conceptually learners in practice settings acquire 'knowledge-in-action' (Gherardi 2000) by interacting with experienced professionals, patients/clients and their peers. But of course some of these interactions take place before and after 'the practice' itself as well as during. Knowing is thus not separate from doing (Gherardi 2000), and is a very different concept from the didactic transfer of knowledge that still occurs to some extent in 'pre-clinical' education. Knowledge-in-action resonates with 'reflection-in-action' as described by Schön (1983): the ability of professionals to think about what they are doing while they are doing it, and to apply knowledge gained through previous experience to new situations. PrBL is active learning and learning by doing (experiential); by learning with and from others, through what may be defined as socially constructed expertise (Manidis \& Scheeres 2012), students begin to develop 'knowing-in-practice' (Gherardi 2000) and this should include how the organisation functions around them. In theoretical terms PrBL is situated learning (Lave \& Wenger 1991), and thus a social collective activity, with the aim of the learner becoming a member of a community of practice (Wenger 1998) pertaining to the clinical environment in which students are placed. So PrBL must involve more than passive observation, though this is acceptable for early clinical contact as long as there is adequate debriefing to allow students to reflect on and discuss what they have seen.

For the health professions, PrBL is an opportunity for interaction with 'real' patients in authentic settings where health care is delivered. Thus, while learning may also occur with simulated patients and in clinical skills laboratories, these settings are only proxies for the complexities of the clinical workplace, which includes patients' homes as well as primary, secondary and tertiary healthcare facilities. A health professional student cannot fully understand the complexity of the working healthcare environment until immersed within it. Yet even with a fair proportion of health professional pre-qualification training taking place within practice, the first few weeks of work as a qualified health professional may still be a shock (see, for example, for nursing Casey et al. 2004; for medicine Brennan et al. 2010). The transition to professional employment from student practice remains difficult, calling into question how well PrBL does facilitate authentic practice and how such facilitation may be improved. We do still lack a clear understanding and theoretical framework for how clinical attachments and the learning therein translate to clinical competency and thus to satisfactory patient/client care (Donnelly \& Wiechula 2012). 
The translation of classroom-based learning and theory into clinical settings is an important component of professional development but, traditionally, has been undertaken through uniprofessional placements albeit within a multiprofessional organisation. Moreover, elements of this prior classroom-based learning may not translate well into complex practice settings, may not resonate with what students observe and are able to practise, and may lead to cognitive dissonance and subsequent change in behaviour. Both informal and hidden curricula are powerful influences on student learning and behaviour, and are features of all health professional clinical education to different degrees. The hidden curriculum is the mechanism by which organisational values are transmitted. It functions from the institutional level right down to an individual learning situation (Thistlethwaite \& Spencer 2008) and has been shown to be one of the most powerful and unrealised influences on student learning and subsequent behaviour in medicine (Hafferty \& Franks 1994), nursing (Treacy 1987) and allied health (Delany \& Molloy 2009). While it may reinforce the formal curriculum it often undermines it.

\section{Required elements of PrBL}

Optimum PrBL experiences require that all involved understand their purpose and role, and that students are adequately prepared for the clinical environment. Supervision must be of high quality, learning activities and tasks should be appropriate and authentic, and assessment must be aligned to learning outcomes and activities (Patrick et al. 2008). The optimal ratio of classroom-based to practice-based learning is difficult to judge. Simply measuring hours of practicum/attachment denies the variability in learning due to the variety of different clinical learning environments, the quality of facilitation and the depth of immersion in and repetition of tasks. There is a great deal of variation between professions in the number and proportion of hours required to be undertaken in practice, and what this practice should entail. However, some accreditation bodies do mandate the length of clinical training. The World Confederation of Occupational Therapists, for example, stipulates that students should have at least 1,000 hours of supervised clinical placements, and 1,000 hours are mandated for physiotherapy, podiatry and speech pathology at some Australian universities, with 500 hours for nutrition and dietetics, and 15 weeks for pharmacy at others (Rose \& Best 2005). In the European Union at least six years of study or 5,500 hours of theoretical and practical training must be provided by universities for basic medical training (GMC 2009). The contents and quality of this training are open to interpretation and medical curricula across Europe vary immensely in terms of patient contact time and hands-on experiences for students.

When considering the elements that constitute a PrBL placement these do vary according to the health professions involved and the universities providing the programmes (Table 2). The clinical environment may be hospital in-patient or out-patient; acute or chronic care facility; operating theatre, intensive care unit or emergency department; general practice, health centre, care home, pharmacy or community clinic. Some courses involve learners visiting patients/clients in their own homes. Students rotate through these different environments for different periods of time and at varying stages of their programmes depending on the formal learning outcomes, availability of supervisors and other resources, and competition across the professions at various sites. The number of students in any one location at any one time may affect the quality of the learning experience both positively and negatively and, potentially, the willingness of patients/clients to be involved in education. Clinical practice is about engaging and interacting with people; 'people' may be health professionals from students' own or others' professions, staff with a direct responsibility for students' learning (e.g. supervisors, tutors, mentors), other students and of course patients/clients. Students practise with all of these. Programme directors (or 
similar) need to ensure they do not practise on patient/clients (a terminology which suggests that patients/clients are inanimate clinical material with no volition).

Clinical education in nursing and medicine has moved from an apprenticeship model, with students having real roles and responsibilities, to their having much more of a supernumerary role within an outcomes-(or competency)-based curriculum. In medicine this move took place following the Flexnerian education revolution of the early 20th century, while in nursing the change was more recent and occurred when nursing came to require a university degree in many countries in the 1990s. Student nurses are no longer paid hospital employees working, and learning, alongside qualified nurses. Just as with medicine, nursing and the other university health professional programmes have followed defined curricula with much more structured learning activities for many decades. Practice is underpinned by knowledge and informed by evidence. Such a foundation has led to the professionalisation of health professionals who were traditionally seen as working 'under' rather than 'alongside' medical doctors. In particular nurses are no longer regarded as doctors' handmaidens but rather as confident and enquiring practitioners who contribute equally to team-based patient care (White 2010).

The broad diversity of the clinical and community settings in which students are placed means that not all students can have exactly the same learning experiences during their programmes. This is not a problem, however, as long as they are able to meet their defined learning outcomes. The majority of these outcomes are generic, and may be achieved in several sites (for example communication, basic clinical skills, relevant physical examinations); a minority are restricted to specific settings such as the operating theatre or emergency department. Similarly there are outcomes that may be met through uniprofessional activities and a smaller number that may only be achieved through interprofessional activities (Thistlethwaite \& Moran 2010).

\section{Length and timing of PrBL}

While learners may be given timetables of where they should be at what time and for how long, learning activities cannot be meticulously planned and are dependent on the availability of patients and tutors. There is a tension between ensuring that students are able to engage in PrBL across many different settings in order to be able to gain a broad experience of the health service and the diversity of clinical experience, and the evidence that suggests situated learning is enhanced through continuity of location and supervision. From my personal experience of health professional education and from talking to colleagues I have noticed the trend in recent times has been for placements to be shorter across the professions, with some being no more than two weeks but others extending to eight weeks or more. As adult learners (Knowles 1990) all health professional students are alike in requiring interaction and there needs to be mutual trust and respect between learner and teacher for learning to take place. Nursing (Papp et al. 2003) and other health professional students need to feel they belong in the clinical environment and that their role is clear to ward staff and, by extrapolation, to staff in other settings.

Shorter placements may enable students to meet their required learning outcomes but questions have been raised within medical programmes about these frequent moves in terms of students being able to feel part of the team, or their experience of 'belongingness' (see, for example, Bell et al. 2008, Ogur et al. 2007). There is no consensus as to how long a specific clinical attachment should be to enable a learner to feel part of the local community of practice. Levett-Jones et al. (2008) found that student nurses felt a greater sense of belongingness the longer their placements and this enhanced their self-efficacy, confidence, capacity and motivation. Research on longitudinal clinical placements for medical students, that is where students are in one location with one supervisor for more than thirteen 
weeks, has shown that these longer attachments enhance students' understanding of the psychosocial aspects of patient care and that such students are more prepared in higher-order clinical skills than students on more traditional and shorter placements (Walters et al. 2012). Though learners beginning a particular placement will be identified as being from a particular year group and at a particular stage of training, supervisors know from experience that not all learners at the same official stage will have the same competencies. For each rotation learners almost need to start again to show they can participate in practice tasks and take responsibility for certain aspects of patient/client care. Thus as learners move from one community of practice to another, both they and their new colleagues/supervisors need time to build trust, and such trust has been shown to be one of the features of the longer rotations (Couper et al. 2001, Frattarelli \& Kamemoto 2004) so students are allowed to take on increasing responsibility for patients. In educational terms these students, who become members of the community of practice, develop legitimate peripheral participation (Lave \& Wenger 1991).

Eraut (2000) has suggested that codified knowledge acquired through teaching and clinical courses, which is an explicit form of knowledge, is very context specific and thus further learning is required to transfer that knowledge to other contexts. However, constant changes to the learning environment through rotation around different clinical settings are unsettling and learning ability is reduced unless orientation is optimal (Thistlethwaite 2010). Different professions, different institutions and different programmes within the same institutions vary in the length of rotations that their students undergo. This length is not necessarily decided on sound educational principles but is chosen because of tradition, logistics and often a desire to have students sample a wide range of clinical disciplines during training. These unequal rotation lengths are one of the barriers to interprofessional placements, as students from different professions do not stay in the same place for the same amount of time.

\section{Supervision and mentorship}

There continue to be major concerns about the capacity for busy service-delivery workplaces to provide adequate PrBL opportunities across all health professions; one limiting factor is the availability of suitably trained educational supervisors or mentors (National Health Workforce Taskforce 2008). The terminology for these educators varies from profession to profession, as do their roles. The Higher Education Academy in the UK defines a 'practice educator' as the 'identified practitioner in the practice placement who facilitates the student learning face to face on a daily basis and generally has responsibility for the formative and/or summative assessment of competence' (HEA 2005, p6) but acknowledges the confusion of nomenclature which includes clinical tutor, educator, trainer, facilitator, preceptor etc. Many have no formal teaching qualification (they are clinicians who teach), no payment and little time for engagement with students. Others have more official academic roles or titles, may combine clinical practice with teaching and may be paid for their time and expertise.

In Scotland there is a new role within nursing, the practice education facilitator (PEF), a role that is 'designed to contribute to the learning environment by providing support, educational input and development activities, and to ensure that nursing and midwifery students... are given a positive and valuable learning experience during practice placements' (Carlisle et al. 2009, p716), which summarises the ideal for these roles. Mentoring would not be the best term as the mentoring role is primarily about support, and practice tutors are also expected to assess their mentees during and at the end of placements. They give judgment on whether students have attained defined competencies, behave professionally and/or are fit to progress to the next stage of training. 


\section{Assessment}

Students are assessed as individuals against the defined learning outcomes of their programmes through a combination of written and clinical examinations, which has been defined as assessing the 'knows how' and 'shows how' of Miller's pyramid (Miller 1990). For PrBL we also need to focus on assessment of performance or 'does': how students perform in authentic clinical settings. This is important as what students demonstrate in controlled assessment environments such as simulations is not necessarily representative of their actual daily work-based performance (Rethans et al. 1991). Work-based assessment (WBA) instruments such as tutor reports, multisource feedback and observation of procedural skills are becoming increasingly common in practice. Each health profession is developing and validating its own instruments, even though there is considerable overlap between the competencies being assessed, for example COMPASS ${ }^{\circledR}$ (competency assessment in speech pathology) (Speech Pathology Australia, available at www. speechpathologyaustralia.org.au/index.php?option=com_content\&view=article\&id=255), APP (assessment of physiotherapy practice) (Griffith University 2010) and the mini-CEX for medicine (Norcini et al. 2003). Portfolios and ePortfolios are also in widespread use for capturing learning and reflection.

\section{Interprofessional learning}

Teamwork is a frequently defined graduate learning outcome in higher education. For the health professions in Australia, teamwork features as one of the standards in, for example, physiotherapy (Australian Physiotherapy Council 2006), nursing and midwifery (RCN 2006), medicine (AHPRA/Medical Board of Australia 2013) and dietetics (Dieticians Association of Australia 2009). There is similar wording in the UK: in medicine students must learn effectively within a multiprofessional team (GMC 2009) and the UK Nursing and Midwifery Council (NMC) requires that students have the opportunity to learn with, and from, other health and care professions so that they can develop the skills they need to work collaboratively with other health and social care professionals (Nursing and Midwifery Council 2010). The inclusion of teamwork outcomes/competencies within curricula concomitantly requires the alignment of learning activities so students can meet the requirements. While such activities may be uniprofessional, it is becoming more common to include teamwork and collaborative practice as activities to be experienced during interprofessional placements.

In addition to the elements required for quality PrBL delivered uniprofessionally, we need to consider other factors when developing interprofessional placements. Again, the nature and length of these placements are often decided on the basis of logistics (timetabling, size of location etc.) and resources as well as on pedagogical principles. For interprofessional practice-based learning activities we need answers to the following questions: is there an optimum number of different professions to be involved? How long should placements be? When should they take place? Is it more effective to have interprofessional immersion if possible rather than have a mix of uniprofessional and interprofessional interventions during the same attachment? What is the best way for students to learn about teamwork and how should we assess this? While there is a growing body of research exploring these questions, workers in this area are usually first asked, 'What is the evidence that IPE is effective?'

There is a lack of longer-term evaluations of IPE (Thistlethwaite 2012). As with most educational research, outcomes-focused evaluation tends to be carried out at the end of interventions and to explore changes in attitudes and knowledge rather than impact on professional behaviour. Published papers primarily focus on innovations in IPE activities and it is difficult to know how sustainable these projects are. However, taken 
together the literature suggests that IPE creates positive interactions and encourages interprofessional collaboration (Thistlethwaite 2012). The BEME (best evidence medical education) systematic review of IPE (Hammick et al. 2007) highlighted the importance of effective facilitation for the delivery of quality interprofessional learning experiences and the importance of these experiences reflecting authenticity of practice to enhance effectiveness. As with uniprofessional PrBL it is important that all students are cognisant of the learning outcomes defined for their interprofessional learning.

While, as stated above, $\operatorname{PrBL}$ is about learning with and from others in a social space, the definition of IPE also includes the preposition 'about' (Freeth et al. 2005). Bainbridge and Wood (2012) have explored the meaning of 'with, from and about others' through a mixed methods approach which included conducting focus groups with students and faculty. They concluded that 'with' requires active engagement between learners; 'from' involves trusting the other learner's knowledge and expertise, and a transfer of knowledge from one to another; while 'about' involves observation of others. Furthermore it emerged from the data that without equity within the learning environment, learning with and from is problematical, a finding that has implications for interprofessional PrBL where students, and certainly clinicians, are not necessarily perceived as equals.

IPE is enhanced not only through formal and informal learning activities but also through what has been called serendipitous learning (Freeth et al. 2005). This learning occurs when students meet 'by accident' such as in shared social spaces including common rooms and accommodation (such as rural clinical placements and those away from the home base). These features of the learning environment are often forgotten and are perhaps not as well developed in clinical settings, particularly in busy hospitals. The hidden curriculum may be an influence here: students observe how health professionals meet, mingle and socialise in hospital canteens and common rooms. Such interactions may model collaborative behaviours or the obverse.

\section{Interprofessional facilitation and role modelling}

When planning interprofessional PrBL activities an important decision is who should supervise a mixed group of students. It is impractical for there to be one of each profession's supervisors for each type of learner. However, accreditation bodies usually mandate that one's own profession should carry out assessment and this needs to be factored into decisions about staffing. Moreover, interprofessional facilitation requires professional development in order to ensure that interprofessional learning is a positive experience. A good facilitator requires the attributes outlined in Table 3 and is not only an interprofessional champion but also an important role model for learners.

Practitioners as role models are important across all practice-based settings and for all health professional students. In relation to interprofessional learning we need to consider whether students are influenced only by role models from their own professions. And a further important question is who role models interprofessionality and/or collaborative practice? Emulating role models is a type of informal learning and is a powerful influence in clinical settings (McAllister et al. 1997). In the chaos and complexity of a new clinical environment, students learn to survive by making alliances with their peers, attaching themselves to clinicians who appear to have time to teach and, sometimes, by keeping a low profile so as not to attract unwelcome attention from their seniors. During this time they may not be able to observe or make sense of the subtleties of teamwork around them. Students will model their own behaviour on those they decide are 'normal' for the workplace in which they are situated (Pollard 2008). If this normality includes collaboration and respect between the professions, they are more likely to view such interactions as the way they too should behave. What may also happen however is that what students 
Table 3 Attributes of effective interprofessional facilitators

- Up-to-date knowledge of educational theory including adult and situated learning theories

- Knowledge and skills relating to the theories of team work and team building

- Experience of working in a health care team

- Experience of collaborative practice and ability to promote this within the workplace

- Understanding of professional roles and responsibilities within the health system

- Awareness of boundary issues including the debate around blurring of professional roles

- Understanding of the process of professional socialisation and how this might impact on interprofessional learning

- Skills in negotiation and conflict resolution

- Interest in and commitment to interprofessional practice

- Ability to take an evidence-guided approach to interprofessional PrBL

(adapted from Thistlethwaite \& Nisbet 2011)

perceive in practice is not what they have been led to believe is the norm from their more theoretical early learning.

Suboptimal collaboration may not be recognised as such by students if they have no standard against which to compare behaviour. In Pollard's (2008) study she found that students did observe lack of information transfer, poor appreciation of another's professional's contribution to patient care and poor interaction across professional and hierarchical boundaries. However, when describing such behaviours students did not recognise them as deficient. Pollard (2008) echoes the concerns of many working in IPE in suggesting that when clinical placements do not support students in working interprofessionally, their collaborative skill acquisition may be hindered.

\section{Interprofessional assessment}

In relation to competency or outcomes-based assessment Lurie has raised the question "why has it been so difficult to crystallise a general consensus about "doing" into a set of specific, well-accepted and measurable competencies?' (Lurie 2012, p50). He critiques examples of the very broad competencies defined by health professional accreditation bodies, noting that many are abstract and socially constructed concepts, which are difficult to translate into observable and therefore assessable behaviours. I would suggest that collaborative practice is such a concept, and even teamwork competencies have been difficult to assess, particularly as students have to be given individual marks by their own profession's examiners for accreditation purposes. Each health profession has its own qualifying criteria which are carried out at the level of an individual student rather than a team; though there may be team-based project work contributing to the overall mark, this will almost certainly be a uniprofessional endeavour.

Further work is required to develop WBA instruments for prequalification interprofessional competencies. The Canadian Interprofessional Health Collaborative (2012) published an inventory of quantitative tools that aim to measure interprofessional and collaborative practice outcomes. The diversity and range of these 128 tools are striking but none are sufficiently suitable for summative assessment of health professional students. The majority focus on change in attitudes - useful for formative feedback. The ubiquitous OSCE (objective structured clinical examination) has been developed by one group as the team-OSCE (or T-OSCE), however there are concerns regarding the validity of assessing teamwork undertaken by a newly formed team (Symonds et al. 2003). 


\section{An example of IP PrBL: the interprofessional training ward}

Space constraints preclude much discussion of the range and diversity of interprofessional PrBL. However, one example of longevity within this area is the student training ward. These wards were first developed and delivered within health professional programmes at Linköping University in Sweden. The health professions usually represented are: nursing, medicine, physiotherapy, occupational therapy and biomedical analysis. Students work on either an orthopaedic or a geriatric ward for two weeks in teams of six and are responsible not only for profession-specific but also generic tasks such as bed-making and handing out meals. The learning outcomes for this practice-based experience build on earlier problem-based learning activities, which aim to help students 'establish a common set of values for professional health care work among these health workers-to-be' (Dahlgren et al. 2012, p193). The ward-based PrBL then facilitates the enactment of these values through the interprofessional work.

The twenty-year review of the Linköping interprofessional training ward has shown that doctors who had graduated from the university over the previous six years reported significantly greater confidence in relation to interprofessional skills and the ability to cooperate with other professions than medical students from other faculties in Sweden (Wilhelmsson et al. 2009).

Training wards are still uncommon outside Sweden and can lead to facilitator burnout and greater length of patient stay (Reeves et al. 2002). Trent Universities Interprofessional Learning in Practice (TUILIP) practice-based learning activities, for instance, have not received particularly positive evaluation, with criticism related to sustainability and level of learning (Furness et al. 2012). Practitioner involvement is important in the design and delivery of IPL activities so that local practices and clinical priorities can be considered and all stakeholders have a shared ownership of the IPL activity.

\section{Conclusion}

Practice-based learning is a blanket term for educational activities aimed at facilitating the transfer of theoretical knowledge into work-based competencies and professional culture. Each health profession has a requirement for students to undertake learning within clinical settings though there are commonalities between the professions in terms of quality and generic learning outcomes. Clinical workplaces are complex environments and the nature of learning within them requires further study.

PrBL has typically been developed and delivered uniprofessionally but the trend towards teamwork in healthcare and the importance of collaborative practice have led to an increase in the numbers of institutions worldwide organising and evaluating interprofessional placements. Successful uniprofessional and interprofessional PrBL requires that learning outcomes are explicit for students and facilitators and learning outcomes are aligned with authentic, relevant and sufficient learning activities and subsequent assessment. In addition interprofessional PrBL requires that students learn and work collaboratively across professions and that there is a supportive workplace culture with experienced interprofessional facilitation and appropriate faculty development.

All practice-based placements are under pressure and there are issues of funding, sustainability and quality. Simulation and a higher proportion of clinical placements being sited in communities have been suggested as ways of dealing with the lack of hospital resources. Further evaluation and research are required to inform and enhance learning and teaching in this area of health professional education. 


\section{References}

AHPRA/Medical Board of Australia (2013) Good medical practice: A code of conduct for doctors in Australia. Available at http://www.medicalboard.gov.au/Codes-GuidelinesPolicies.aspx (accessed 7 January 2103).

Australian Physiotherapy Council (2006) Available at www.physiocouncil.com.au/files/ the-australian-standards-for-physiotherapy (accessed 7 January 2013).

Bainbridge, L. and Wood, V.I. (2012) The power of prepositions: Learning with, from and about others in the context of interprofessional education. Journal of Interprofessional Care 26, 452-458.

Bell, S.K., Krupat, E., Fazio, F.B., Roberts, D.H. and Schwartzstein, R.M. (2008) Longitudinal pedagogy: a successful response to the fragmentation of the third-year medical student clerkship experience. Academic Medicine 83, 467-475.

Brennan, N., Corrigan, O., Allard, J., Archer, J., Barnes, R., Bleakley, A. et al . (2010) The transition from medical student to junior doctor: today's experiences of Tomorrow's Doctors. Medical Education 44, 449-458.

Canadian Interprofessional Health Collaborative (2012) An inventory of qualitative tools measuring interprofessional education and collaborative practice outcomes. Available at www.chd.ubc.ca/files/file/instructor-resources/CIHC_tools_report_Aug26\%202012.pdf (accessed 7 January 2013).

Carlisle, C., Calman, L. and Ibbotson, T. (2009) Practice-based learning: The role of practice education facilitators in supporting mentors. Nurse Education Today 29, 715-721.

Casey, K., Fink, R., Krugman, M. and Propst, J. (2004) The graduate nurse experience. Journal of Nursing Administration 34, 303-311.

Costa, D.M. and Burkhardt, A. (2003) The purpose and value of occupational fieldwork education (2003 statement). American Journal of Occupational Therapy 32, 246-251.

Couper, I., Worley, P.S. and Strasser, R. (2001) Rural longitudinal integrated clerkships: lessons from two programs on different continents. Rural Remote Health 11 (2), 1665.

Dahlgren, M.A., Dahlgren, L.O. and Dahlberg, J. (2012) Learning professional practice through education. In Practice, learning and change: practice-theory perspectives on professional learning (eds. P. Hager, A. Lee and A. Reich). Sydney: Springer, pp183-198.

Delany, C. and Molloy, E. (2009) Clinical education in the health professions: an educator's guide. Chatswood, NSW: Elsevier.

Dieticians Association of Australia (2009) Available at http://daa.collaborative.net.au/files/ WorkingandStudying/2010_ELC_Brochure_Inside_Word_VersionEXACT.pdf (accessed 7 January 2013).

Donnelly, F. and Wiechula, R. (2012) Clinical placement and case study methodology: a complex affair. Nurse Education Today 32, 873-877.

Entwistle, N. (2009) Teaching for understanding at university. Deep approaches and distinctive ways of thinking. Basingstoke: Palgrave Macmillan.

Eraut, M. (2000) Non-formal learning and tacit knowledge in professional work. British Journal of Educational Psychology 70, 113-136.

Frattarelli, L.C. and Kamemoto, L.E. (2004) Obstetrics and gynecology medical student outcomes: longitudinal multispecialty clerkship versus traditional block rotations. American Journal of Obstetrics and Gynecology, 191 (5), 1800-1804. 
Freeth, D., Hammick, M., Reeves, S., Koppel, I. and Barr, H. (2005) Effective interprofessional education: development, delivery and evaluation. Oxford: Blackwell.

Furness, P.J., Armitage, H.R. and Pitt, R. (2012) Qualitative evaluation of interprofessional learning initiatives in practice: application of the contact hypothesis. International Journal of Medical Education 3, 83-91.

Gherardi, S. (2000) Practice-based theorizing on learning and knowing in organizations. Organization 7 (2), 211-223.

GMC (2009) Tomorrow's doctors. London: General Medical Council.

Griffith University (2010) Available at www.griffith.edu.au/_data/assets/pdf_file/0011/78392/

Griffith-mid-and-end-unit-APP_2010.pdf (accessed 17 December 2012).

Hafferty, FW. and Franks, R. (1994) The hidden curriculum, ethics teaching and the structure of medical education. Academic Medicine 30, 861-71.

Hammick, M., Freeth, D., Koppel, I., Reeves, S. and Barr, H. (2007) A best evidence systematic review of interprofessional education. Medical Teacher 29, 735-51.

HEA. (2005) Occasional paper 6. Making practice-based learning work. London: HEA. Available at: http://repos.hsap.kcl.ac.uk/content/m10141/latest/occp6.pdf (accessed 17 December 2012).

Knowles, M. (1990) The adult learner: a neglected species. 4th edition. Houston: Gulf Publishing.

Lave, J. and Wenger, E. (1991) Situated learning: legitimate peripheral participation. Cambridge University Press.

Levett-Jones, T., Lathlean, J., Higgins, I. and McMillan, M. (2008) The duration of clinical placements: a key influence on nursing students' experience of belongingness. Australian Journal of Advanced Nursing 26 (2), 8-16.

Lurie, S.J. (2012) History and practice of competency-based assessment. Medical Education 46, 49-57.

Manidis, M. and Scheeres, H. (2012) Towards understanding workplace learning through theorising practice: at work in hospital emergency departments. In: Practice, learning and change: practice-theory perspectives on professional learning (ed. P Hager et al.), pp103-118.

McAllister, L., Lincoln, M., McLeod, S. and Maloney, D. (1997) Facilitating learning in clinical settings. Cheltenham: Nelson Thornes.

Miller, G. (1990) The assessment of clinical skills/competence/performance. Academic Medicine 165 (supplement), 63-67.

Norcini, J.J., Blank, L.L., Duffy, F.D. and Fortna, G.S. (2003) The mini-CEX: a method for assessing clinical skills. Annuals of Internal Medicine 138, 476-481.

Nursing and Midwifery Council (2010) Standards for pre-registration nursing education: draft for consultation. London: NMC.

Ogur, B., Hirsh, D., Krupat, E. and Bor, D. (2007) The Harvard Medical School-Cambridge integrated clerkship: an innovative model of clinical education. Academic Medicine 82, 397-404.

Papp, I., Markkanen, M. and von Bonsdorff, M. (2003) Clinical environment as a learning environment: student nurses' perceptions concerning clinical learning experiences.

Nurse Education Today 23, 262-268. 
Patrick, C.-J., Peach, D., Pocknee, C., Webb, F., Fletcher, M. and Pretto, G. (2008) The WIL [Work Integrated Learning] report: A national scoping study [Australian Learning and Teaching Council (ALTC) Final Report].

Pollard, K.C. (2008) Non-formal learning and interprofessional collaboration in health and social care: the influence of the quality of staff interaction on student learning about collaborative behaviour in placement settings. Learning in Health and Social Care 7, 12-26.

RCN (2006) The Royal College of Nursing Australia Competency Standards. Available at http://anf.org.au/pages/competency-standards (accessed 7 January 2013).

Reeves, S., Freeth, D., McCrorie, P. and Perry, D. (2002) 'It teaches you what to expect in the future...': interprofessional learning on a training ward for medical, nursing, occupational therapy and physiotherapy students. Medical Education 36, 337-344.

Rethans, J., Sturmans, F., Drop, R., van der Vleuten, C. and Hobus, P. (1991) Does competence of general practitioners predict their performance? Comparison between examination setting and actual practice. BMJ 303, 1377-1380.

Rose, M. and Best, D. (2005). Context for clinical education, professional supervision and mentoring. In Transforming practice through clinical education, professional supervision and mentoring (eds. M. Rose and D. Best). Chatswood, NSW: Elsevier. pp8-15.

Schön, D. (1983) The reflective practitioner. New York: Basic Books.

Scotland, QAA (2011) Key aspects of practice-based learning in teaching, nursing and social work in Scotland. Glasgow: QAA. Available at www.qaa.ac.uk/Publications/ InformationAndGuidance/Dcouments/Practice-based-learning-guidance.pdf.

Symonds, I, Cullen, L. and Fraser, D. (2003) Evaluation of a formative interprofessional team objective structured clinical examination (ITOSCE): a method of shared learning in maternity education. Medical Teacher 25, 38-41.

Taskforce, National Health Workforce (2008) Data, capacity and clinical placements across Australia: a discussion paper. Melbourne: NHWT.

Thistlethwaite, J.E. (2010) Learning environment. In ABC of learning and teaching in medicine (eds. P. Cantillon and D. Wood), pp60-63. London: Wiley-Blackwell.

Thistlethwaite, J.E. (2012) Interprofessional education: a review of context, learning and the research agenda. Medical Education 46, 58-70.

Thistlethwaite, J.E. and Moran, M. (2010) Learning outcomes for interprofessional education (IPE): literature review and synthesis. Journal of Interprofessional Care 24, 503-513.

Thistlethwaite, J.E. and Nisbet, G. (2011) Preparing educators for interprofessional learning: rationale, educational theory and delivery. In A sociological perspective on interprofessional education (eds. S. Kitto, J. Chester, S Reeves and J. Thistlethwaite), pp169-184.

New York: Nova4.

Thistlethwaite, J.E. and Spencer, J. (2008) Professionalism in medicine. Oxford: Radcliffe Medical Press.

Treacy, M.P. (1987) Some aspects of the hidden curriculum. In The curriculum in nursing education (eds. P. Allan and M. Jolley), pp164-175. Beckenham: Croom Helm Ltd.

UNISA (nd) University of South Australia. Learning and Teaching Unit. Teaching in Higher Education. Practice-based learning. Available at http://w3.unisa.edu.au/ academidevelopment/engagement/practice.asp (accessed 17 December 2012). 
Walters, L., Greenhill, J., Richards, J., Ward, H., Campbell, N., Ash, J. et al. (2012) Outcomes of longitudinal integrated clinical placements for students, clinicians and society. Medical Education 46, 1028-1041.

Wenger, E. (1998) Communities of practice: learning, meaning, and identity. Cambridge: Cambridge University Press.

White, C. (2010) A socio-cultural approach to learning in the practice setting. Nurse Education Today 30, 794-797.

Wilhelmsson, M., Pelling, S., Ludvigsson, J., Hammar, J., Dahlgren, L-O. and Faresjö, T. (2009) Twenty years experience of interprofessional education in Linköping ground-breaking and sustainable. Journal of Interprofessional Care 23, 121-133.

Williams, C. (2010) Understanding the essential elements of work-based learning and its relevance to everyday clinical practice. Journal of Nursing Management 18, 624-632.

Zukas, M. and Kilminster, S. (2012) Learning to practise, practising to learn: doctors' transitions to new levels of responsibility. In Practice, learning and change: practice-theory perspectives on professional learning (eds. P. Hager, A. Lee, A. Reich), pp199-213. Sydney: Springer. 